\title{
Significance enhancement in the conductivity of core shell nanocomposite electrolyte
}

Asia Rafiquea, ${ }^{b}$, Rizwan Raza ${ }^{\mathrm{a}, \mathrm{c}^{*}}$, Nadeem Akramª, M. Kaleem Ullah ${ }^{\mathrm{a}}$, Amjad Ali ${ }^{\mathrm{a}}$, Muneeb Irshadd, ${ }^{\mathrm{e}}$, Khurram Sirajd, ${ }^{\mathrm{e}}$, M.Ajmal Khan ${ }^{\mathrm{a}}$, Bin Zhuc, ${ }^{\text {, }}$,Richard Dawson ${ }^{\mathrm{g}}$

Today, there is great demand of electrolytes with high ionic-conductivity at low operating temperatures for solid-oxide fuel cells. Therefore, a co-doped technique was used to synthesize a highly ionically conductive two phase nanocomposite electrolyte $\mathrm{Sr} / \mathrm{Sm}$-ceria-carbonate by coprecipitation method. A significant increase in conductivity was measured in this co-doped $\mathrm{Sr} / \mathrm{Sm}$ ceria-carbonate electrolyte at $550 \mathrm{oC}$ as compared to the more commonly studied samarium doped ceria. The fuel cell power density was $900 \mathrm{~mW} / \mathrm{cm} 2$ at low temperature $\left(400-580^{\circ} \mathrm{C}\right)$. The composite electrolyte was found to have homogenous morphology with core-shell structure using SEM and TEM. The two phase core-shell structure was confirmed from XRD analysis. The crystallite size was found to be $30-60 \mathrm{~nm}$ and is in good agreement with the SEM analysis. The thermal analysis was determined with DSC. The enhancement in conductivity is due to two effects; co-doping of Sr in samarium doped ceria and it's composite with carbonate which is responsible for core-shell structure. This co-doped approach with the second phase gives promise in addressing the challenge to lower the operating temperature of solid oxide fuel cells (SOFC).

a. Department of Physics, COMSATS Institute of Information Technology, Lahore 54000, Pakistan

b. Higher Education Department, Govt. of Punjab, Pakistan

c. Department of Energy Technology, Royal Institute of Technology (KTH), 10044, Stockholm, Sweden

d. Laser \&Optronics Center, Department of Physics, University of Engineering and Technology, Lahore 54000, Pakistan

e. Department of Physics, University of Engineering and Technology, Lahore 54000, Pakistan

f. Hubei Collaborative Innovation Center for Advanced Materials, Faculty of Physics and Electronic Technology, Hubei University, Wuhan, Hubei 430062, P.R. China

g. Engineering Department Lancaster University, Lancaster LA1 4YR, UK

*Email: razahussaini786@gmail.com, binzhu@kth.se

\section{Introduction}

Solid oxide fuel cells (SOFCS) are achieving significant attention for power generation due to certain attractive features including fuel flexibility, high efficiency and potentially long operating lives 1. However, the high operating temperature range of traditional SOFCs $\left(>900^{\circ} \mathrm{C}\right)$ puts many constraints on system design and is particularly challenging for the choice of materials2. Therefore, substantial efforts are in progress to lower the operating temperature regime, known as intermediate temperature (IT) range $\left(500-750^{\circ} \mathrm{C}\right) 3$. Lowering the operating temperatures however leads to decreased performance (lesser oxygen ion conductivity). One approach to maintain the higher conductivity is to reduce the thickness of electrolyte to minimize its ohmic resistance, but it has experienced certain limitations including a threshold thickness after which the resistance does not decrease4. The other approach is to explore and develop new electrolyte materials possessing high ionic conductivity, at low temperatures 4. 
Many oxygen ion conductors have been extensively studied as an electrolyte in SOFCs,5-8 and based on various families ceramic crystal structures, such as perovskites, fluorites, apatite, pyrochlore, melilite, brownmillerite, BIMEVOX, LAMOX9-13. However, the fluorite structured materials i.e ceria (CeO2), zirconia ( $\mathrm{ZrO} 2$ ) and $\mathrm{Bi} 2 \mathrm{O} 3$ are considered as ideal oxide ion conductors. Ideal fluorite structure is a face centered cubic (FCC) array of cations, while anions sit on the tetrahedral sites, where the conduction mechanism occurs in the anion sub-lattices by means of 'vacancy migration'. Only ceria ( $\mathrm{CeO} 2$ ) retains its fluorite structure at room temperature, while both $\mathrm{ZrO} 2$ and $\mathrm{Bi} 2 \mathrm{O} 3$ have monoclinic structures which can be stabilized with other cation like yttria.

At intermediate temperature range, the performance of SOFC is largely dominated by two processes which are; the oxygen reduction reaction (ORR) that occurs at the cathode and the ionic conductivity of the electrolyte 5.Yttria stabilized zirconia (YSZ) as an electrolyte is a good choice and is reliable due to its structural and thermodynamic stability. But it possess low ionic conductivity at IT range although a conductivity of $4.2 \times 10-2 \mathrm{~S} / \mathrm{cm}$ at temperature $800^{\circ} \mathrm{C}$ has been reported 6 . Also Bi2O3 showed highest conductivity of $1 \mathrm{~S} / \mathrm{cm}$ keeping its fluorite structure but within a very narrow temperature range, $730-804{ }^{\circ} \mathrm{C} 14,15$. These structural changes be avoided by appropriate doping for example; for Bi1.6Er0.4O3, $2 \times 10-2 \mathrm{~S} / \mathrm{cm}$ conductivity is reported at $500{ }^{\circ} \mathrm{C}$, while high conductivities of 10-3-10-2 S/cm has been achieved for Bi12.5La1.5ReO24.5 and Bi0.85Pr0.105V0.04501.545 at temperatures $300-400{ }^{\circ} \mathrm{C} 9,16-17$.

Among these fluorite structured materials, ceria ( $\mathrm{CeO} 2)$ based materials are attracting a great amount of interest as electrolytes for SOFC due to their high conductivity at lower temperatures and good stability. In reducing atmosphere, ceria doped with rare earth elements is partially reduced and exhibits electronic conductivity, 18 with typical peak conductivity $(-0.01 \mathrm{~S} / \mathrm{cm})$ reported at $500{ }^{\circ} \mathrm{C}$ Ce0.8Sm0.201.9 and Ce0.9Gd0.101.95,19 and is potentially a significant problem which must be mitigate in any practical device. In ceria, the ionic conductivity is related to the formation of oxygen vacancy and its migration,20,21and these vacancies are produced for compensating dopant cations. Though pure ceria is a poor oxide-ion conductor as low conductivity of $10-5 \mathrm{~S} / \mathrm{cm}$ doping results in an increased concentration of oxygen vacancies according to the reaction 2 .

$\mathrm{MO} \square\left(\rightarrow \perp\left(\mathrm{CeO}_{-} 2\right)\right) \mathrm{M} \_\mathrm{Ce}^{\wedge}+\mathrm{OO}+\mathrm{V} \_\mathrm{O}^{\wedge}(\cdot \bullet)$

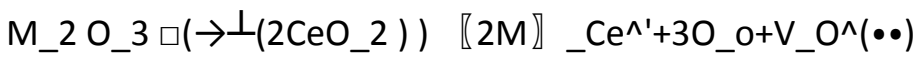

Where $\mathrm{M}$ is divalent cation $(\mathrm{M} 2+=\mathrm{Mg}, \mathrm{Ca}, \mathrm{Sr}, \mathrm{Ba}$ ) or trivalent cation ( $\mathrm{M} 3+=\mathrm{Sm}, \mathrm{Gd}$ etc.)23.

The oxygen vacancy in doped ceria depends on the nature of the dopant and its amount 24,25 . Its ionic conductivity is also affected by the 'lattice strain' as generated due to the ionic-radius mismatch between the dopant and host ions 3 . Therefore, it is very important to have an appropriate choice of dopant and its amount to minimize the lattice strain and consequently to enhance the ionic conductivity26-29. It has been reported that sufficient oxygen vacancies are produced by doping of $20 \mathrm{~mol} \%$ divalent or trivalent cation in ceria,30 for example samarium doped ceria (SDC) and gadolinium doped ceria (GDC)26, 31. But there is deterioration of the ionic conductivity of $\mathrm{CeO} 2$ due to the clustering of oxygen vacancy (or defect association) as the trivalent dopant $(\mathrm{M} 3+)$ content increases above $20 \%$ mol, which leads to the generation of few mobile vacancies 32.

For ceria doped with different cations, only samaria doped ceria (SDC) has showed highest conductivity as reported by Eguchi et al.,33 as the ionic radius of samaria (1.079 $\AA$ ) matches with ceria $(0.94 \AA)$. Although, it is considered that minimum difference of 'ionic radii mismatch' between dopant and host results in the increase of conductivity 34-35. But it does not seem always 
acceptable because the ionic radius of yttria (1.019 $\AA)$ is closer to ceria as compared to samaria 36 . Therefore, it is still debatable whether only the ionic radius of the dopant determines the oxide ion conductivity or some other parameters also plays an important role.

However, are cognized route for improving the ionic conductivity of such fluorite structured materials is co-doping (also known as doubly doped) i.e. doping with two or more than two differentiation species5. This approach was first employed by Politova and Irvine, 37 for solid electrolytes, when they studied the doping of scandia (scandium) and yttria (yttrium) with zirconia. They reported that only a small content of yttria (yttrium) is necessary for stabilizing the cubic fluorite-structure, as further addition of it to Sc-doped ZrO2 decreases the conductivity of material37. However, contrary to the role of co-doping in $\mathrm{ZrO} 2$ for stabilizing its structure, co-doping (it) can be used in $\mathrm{CeO} 2$ for increasing its ionic conductivity by reproducing the ionic radius of the ideal dopant or the lattice constant. The purpose of the doping is to achieve an effective or average cation radius, very close to ceria; hence to minimize the 'average strain' as developed by dopant cations5. Co-doping effects of different trivalent metals like $\mathrm{Y}, \mathrm{Sm}, \mathrm{Nd}, \mathrm{Pr}$, La on gadolinia doped ceria (GDC) were studied by Kim et al.,38 and found an increase in ionic conductivity with Sm codoping. Yamamura et al.,39 discussed the effect of co-doping on the system Ce1-x-yLaxMyO2- $\delta$ with $\mathrm{M}=\mathrm{Ca}$ or Sr. For singly (Ce0.8Ln0.2O1.9, where $\mathrm{Ln}=\mathrm{Y}, \mathrm{Sm}, \mathrm{Nd}, \mathrm{La}$ ) and doubly doped ceria (Ce0.8La0.1Y0.101.9), the ionic conductivity was investigated by Yoshida et al.,40 using extended $\mathrm{x}$ ray absorption fine structure (EXAFS). Andersson et al. calculated theoretically using DFT the effect of co-doping in ceria with $\mathrm{Nd} / \mathrm{Sm}$ and $\mathrm{Pr} / \mathrm{Gd}$ and predicted that it can enhance the ionic conductivity as compared to singly doped ceria 41 . Omer et al.,42reported an increase in ionic conductivity $(0.014$ $\mathrm{S} / \mathrm{cm}$ at $550^{\circ} \mathrm{C}$ ) with $\mathrm{Ce} 0.85 \mathrm{Nd} 0.075 \mathrm{Sm} 0.07501 .925$, based on these theoretical backgrounds, 41 which was $30 \%$ as compared to Ce0.9Gd0.101.95. Similar results were reported by Ramesh et al.,43 for co-doping of Gd and Pr with ceria and found $11.5 \%$ higher ionic conductivity than GDC. Sha et al.,44 studied the effect of co-doping of $L a$ and $Y$ with ceria and found an improvement in the ionic conductivity. Yeh and Chou,30investigated co-doping of strontium (1.25 $\mathrm{A})$ with SDC and achieved good conductivity of $0.061 \mathrm{~S} / \mathrm{cm}$ with $\mathrm{Ce} 0.78 \mathrm{Sm} 0.2 \mathrm{Sr} 0.0201 .88$ at $800{ }^{\circ} \mathrm{C}$ which was twice of singly doped SDC. Recently, Gao et al.,45reported an increase in the bulk conductivity for Ce0.8(Sm0.7 Sr0.3)0.2O2- $\delta$.

The co-doping is a good approach for the structure modification of ceria-based material to improve the ionic oxide conductivity at low temperature range (300-600 oC). Sr is very attractive due to its distinctive co-doping effect into the ceria host lattice and the ionic-radius compatibility with the host cation 19. The introduction of the co-doped ceria with $\mathrm{Sr}$ can lead to the improved ionic conductivity 30,46 . The ionic conductivity of co-doped ceria can be further increased by introducing carbonates as a second phase. The carbonate phase as a core-shell structure provides interface for ion conduction and is reported in our previous work 47-49.

In this paper, we report first time on co-doping of carbonate based ceria composite with different concentrations/compositions of Sr and Sm for electrolytes suitable for IT-SOFC. The crystal structure and surface morphology of the synthesized electrolyte materials was studied by $X$-ray diffraction (XRD), scanning electron microscopy (SEM) and Energy-dispersive X-ray spectroscopy (EDX). The existence of second phase responsible for core-shell structure is confirmed by TEM analysis. We measured an increased ionic conductivity at low temperature range and consequently the enhanced performance of the fuel cell.

\section{Experimental}




\section{Sample/Electrolyte Preparation}

$\mathrm{Sr} \& \mathrm{Sm}$ co-doped ceria core with $\mathrm{Na} 2 \mathrm{CO} 3$ carbonate shell is named as nanocomposite electrolytes

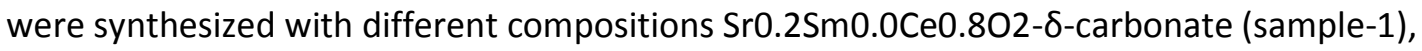
Sr0.2Sm0.1Ce0.7O2- $\delta$-carbonate (sample-2), Sr0.1Sm0.2Ce0.702- $\delta$-carbonate (sample-3) and Sr0.1Sm0.1Ce0.802- $\delta$-carbonate (sample-4) by a co-precipitation technique47,50. Stoichiometric amounts of cerium nitrate hexahydrate $\mathrm{Ce}(\mathrm{NO} 3) 3.6 \mathrm{H} 2 \mathrm{O}$ (Sigma Aldrich 99\%, USA), samarium nitrate hexahydrate $\mathrm{Sm}(\mathrm{NO} 3) 3.6 \mathrm{H} 2 \mathrm{O}$ (Sigma Aldrich 99\%, USA) and strontium nitrate $\mathrm{Sr}(\mathrm{NO} 3) 2$ (Sigma Aldrich 99\%, USA) were mixed and dissolved in de-ionized water to make a $0.1 \mathrm{M}$ solution. The nitrate solution was stirred for 2 hours and $0.2 \mathrm{M} \mathrm{Na} 2 \mathrm{CO} 3$ solution was prepared and added drop wise in the nitrate solution. The resulting precipitate was rinsed with de-ionized water and then dried in oven at $250^{\circ} \mathrm{C}$ for 2 hours. The dried powder was subsequently calcined $850{ }^{\circ} \mathrm{C}$ in furnace for 4 hours. The same procedure was used to prepare all the samples.

The solid state reaction (SSR) method was used to prepare the Li-Ni-Cu-Zn (LNCZ) oxide electrodes. Li2CO3.3H2O (Sigma Aldrich, 99\% USA), Ni2(CO3)3.6H2O (Sigma Aldrich,99\% USA), Cu(CO3)3 (Sigma Aldrich, 99\%USA) and Zn(NO3)2. (Sigma Aldrich, 99\%USA) were mixed in a weight ratio of 1.5: 7: 2.5: 7. These were grinded in mortar pestle and then calcined for 4 hours at $800 \mathrm{oC}$. Nickel and copper oxides were used as a catalyst in the anode.

\section{Characterization}

The calcined powdered samples were characterized by X-ray diffraction analysis (XRD) using X-ray diffractometer (PANalytical X'Pert Pro MPD, Phillips, Netherlands) with monochromated Cu K $\alpha$ radiation $(\lambda=0.15418 \mathrm{~nm})$. The lattice constant and lattice parameter of the materials were determined from the XRD peaks. The average crystallite size $D$ was determined by using the Scherer's equation:

$\mathrm{D}=(0.9 \lambda) /(\beta \cos \theta)$

Where $\lambda$ is the wavelength of radiation, $\beta$ is the full width at half maximum (FWHM) of the peak and $\theta$ is the Bragg angle51. $\beta$ is taken for the strongest Bragg's peak corresponding to (111) reflection for all the samples.

The microstructure and morphology of the samples were examined using scanning electron microscope (FE-SEM, Carl Zeiss, Germany). In order to confirm the second phase (core-shell) and microstructure analysis TEM was performed on a JEOL NM-200 and operated at $200 \mathrm{kV}$. The thermal behaviors of the composite electrolytes were investigated by thermogravimetry analysis (TGA) (model Q600, USA), and the samples were heated from 25 oC to 1000 oC at a rate of 10 oC min-1. The thermal expansion co-efficient and change in volume of solids were measured using a NETZSCH model $402 \mathrm{C}$ pushrod dilatometer. This dilatometer was equipped with a SiC furnace capable of operation between room temperature and $1600^{\circ} \mathrm{C}$. The system is vacuum tight, allowing measurements to be carried out in pure inert or oxidizing atmospheres, as well as under vacuum.

Pellet fabrication for conductivity and performance measurement

For conductivity measurements, $1.15 \mathrm{~mm}$ thick pellets with $13 \mathrm{~mm}$ diameter having an active area of $0.84 \mathrm{~cm} 2$ were made with the different compositions of the electrolyte under $40 \mathrm{MPa}$ pressure and sintered in air at $700{ }^{\circ} \mathrm{C}$ for 60 minutes. To collect/measure the current, silver paste was used on both sides of the pellet and dried at $600{ }^{\circ} \mathrm{C}$ for $30 \mathrm{~min}$. The conductivity of the sintered samples was measured by four point $\mathrm{dc}$ probe method at $\left(300-600^{\circ} \mathrm{C}\right)$ temperature range in air. The distance between voltage probe and current probe was kept as $1.2 \mathrm{~mm}$. The Probe station (KeithLink, China) 
with 4 probes of Tungsten integrated with DC current source 2450 (Keithley Instruments, USA) were used for current and voltage measurements. The conductivity was calculated using the collected data from KickStart software (Keithley instruments, USA), with the following formula;

$$
\sigma=\mathrm{L} / \mathrm{RA}
$$

where $\sigma$ is the conductivity, $L$ is the thickness of the pellet, $R$ is the internal resistance is and $A$ is the area of the cell. The active area of the pellet was assumed to be $0.64 \mathrm{~cm} 2$.

For fuel cell pellets fabrication, same procedure was used to make the cells ( $\mathrm{LNCZ}+\mathrm{Sr}$-SDC|SrSDC|LNCZ+Sr-SDC). Fuel cell was $13 \mathrm{~mm}$ in diameter and $0.8 \mathrm{~mm}$ in thickness (anode thickness 0.30 $\mathrm{mm}$, electrolyte $0.30 \mathrm{~mm}$ and cathode $0.20 \mathrm{~mm}$ ), so the cell has an electrolyte supported configuration. The cell performance was measured with a computerized instrument (Fuel Cell Electronic load, Model: IT8511, China) at $600^{\circ} \mathrm{C}$ and $\mathrm{H} 2$ gas was used as a fuel with a flow rate of 100 $\mathrm{ml}$.min-1 at atmospheric pressure and ambient air was used as an oxidant.

\section{Results and discussion}

\section{Phase analysis and microstructure}

Fig. 1 displays the pattern of XRD for co-doped Sr/Sm ceria-carbonate electrolyte with different compositions which are indexed by using the Mjad-5 software. The indexed patterns are showed that all the compositions have a single phase of CeO2oxide, and clearly seen that both $\mathrm{Sr}$ and $\mathrm{Sm}$ have been doped properly in ceria. It also shows that all co-doped ceria electrolytes have cubic fluorite structure (JCPDS Card No.39-0394). The values of angle $2 \theta$ of doped ceria shift slightly with change in the composition of $\mathrm{Sr}$ and $\mathrm{Sm}$. The average crystallite size of each composition was calculated form peak data of ceria phase by using the Scherer's equation and is shown in the Table 1.The results showed that the composition $\mathrm{Sr} 0.1 \mathrm{Sm} 0.1 \mathrm{Ce} 0.8 \mathrm{O} 2-\delta$-carbonate has the smallest average crystallite size $29.637 \mathrm{~nm}$. It can also be seen that lattice parameter of ceria oxide are varied with the ratios of $\mathrm{Sr}$ and $\mathrm{Sm}$ contents. This lattice parameter of ceria oxide are changed due to due to slightly difference of ionic radii of Ce4+ $(0.94 \AA)$ with Sm3+ (1.079 $)$ and Sr2+ $(1.25 \AA)$. These values are in complete agreement with Vegord's rule and also verify that the prepared samples of doped ceria are indeed ceria based solid solution.

The microstructural morphologies for all compositions of as prepared powder/electrolytes were studied using SEM. Fig 2(a) shows the typical microstructure of Sr0.1Sm0.1Ce0.802- $\delta$-carbonate and indicating that particles are homogeneous and distributed uniformly. In Fig 2(a), it can also be observed that the prepared electrolyte is not porous and is quite dense. The particle shapes are irregular and the average size is $30-60 \mathrm{~nm}$, which agrees adequately with the XRD analysis.

Micrograph of fig 2(a) clearly represents the carbonate phase or second phase with the ceria phase, as there is a distinct contrast between the inner and outer shell of the particles. This indicates the presence of core-shell structure as the percolation of amorphous carbonates is obvious. Such two phase regions facilitate the ionic conduction by constructing ion conducting paths 48 . In order to confirm the carbonate phase and contents in the electrolyte, EDX spectrum was also performed and fig. 2(b) shows the formation of Na2CO3-core shell on Sr-SDC. The amorphous nature of the shell can also be verified from the XRD pattern which shows no peak of $\mathrm{Na2CO3}$. This also compliments the SEM analysis which reveals the shallow layer of $\mathrm{Na} 2 \mathrm{CO} 3$ on the particles. 
The high-resolution TEM image of a small part of co-doped ceria shows the crystal structure and particle size in fig. 2(c). The presence of secondary phase and core shell was observed and shown in fig. 2(c). It can be clearly seen that shell layer is very thin and, several $\mathrm{nm}$ in thickness, was formed outside the co-doped Sr-SDC particle.

The formation of core shell layer will act as a barrier to electronic conduction between anode and electrolyte. This shell will protect SDC from partial reduction by the fuel thus further reducing any electronic current.

\section{Thermal Analysis}

Fig. 3(a) and (b) describe the temperature-dependent mass variations and heat flow rate of the ceria co-doped nanocomposite electrolyte in air and reducing varigon atmospheres at room temperature to $650 \mathrm{oC}$. In the temperature range of $25 \mathrm{oC}$ to $150 \mathrm{oC}$, a mass loss step of $2.9 \%$ was observed in varigon and air environments due to the evaporation of absorbed moisture/water, which was escorted by an endothermic DSC peak with an enthalpy of $\sim 66 \mathrm{~J} / \mathrm{g}$. In the next step of temperature range $150 \mathrm{oC}$ to $400 \mathrm{oC}$, further mass loss of $0.4-0.5 \%$ occurred, which could be due to the burn-up of impurities in ceria co-doped nanocomposite electrolyte. Above the temperature of $400{ }^{\circ} \mathrm{C}$, there was no mass loss to observe in the air atmosphere, but in the varigon environment showed $0.5 \%$ mass loss which is due to reduction environs. A small endothermic DSC peak was observed around the temperature of $600{ }^{\circ} \mathrm{C}$ in both air and reducing varigon atmospheres, where the phase transformation may be occurred.

In order to evaluate the mechanical compatibility of the $\mathrm{ZnO} / \mathrm{NiO}$ materials with the electrolyte, thermal expansion measuremts were performed. Fig. 3(b) illustrates the varations of the $\Delta \mathrm{L} / \mathrm{L}$ (coefficent of linear expansion) values in the range of 300-550 oC. It shows good match of the $\mathrm{ZnO} / \mathrm{NiO}$ materials and $\mathrm{Sr} / \mathrm{Sm}$ ceria-carbonate in the air. In the $\mathrm{H} 2$ atmosphere, it shows a shringkage of $\mathrm{ZnO} / \mathrm{NiO}$ materials due to the $\mathrm{Ni}-\mathrm{Zn}$ phase formation with $\mathrm{ZnO} / \mathrm{NiO}$ reduced by $\mathrm{H} 2$ and succedent $\mathrm{Ni}-\mathrm{Zn}$ transformation around $530 \mathrm{oC}$. In the application of low temperature (LT) SOFCs stack using $\mathrm{ZnO} / \mathrm{NiO}$ electrodes, it should be opearted lower than $530 \mathrm{oC}$ in order to prevent the mechanical degradation of the electrode. It can been seen from the fig. 3(b) that with increasing temperature, the difference between the curves of samples exposed to different ambient conditions also increases. In the case of $\mathrm{Sr}$ doped samples the difference between the curves is not very significant as compared to the $\mathrm{ZnO} / \mathrm{NiO}$ for different ambient environment due to fact that degradation in $\mathrm{ZnO} / \mathrm{NiO}$ samples starts at higher temperatures.

\section{Conductivity and Cell Performance}

As discussed earlier, there are two major challenges for the commercialization of SOFC, one is to lower the operating temperature and second is to explore new, more cost-effective, and stable materials/compositions. Here the Sr-divalent cation has been used as a co-dopant due to its low cost and easy availability 51 . From fig $4(\mathrm{a})$, it can be seen that $\mathrm{Sr} / \mathrm{Sm}$ ceria-carbonate system shows higher ionic conductivity at low temperature as compare to singly doped ceria with same conductivity at $1000 \mathrm{oC}$. Furthermore, the co-doing of Sr in SDC and carbonate as core shell could help to overcome the electronic conduction of $\mathrm{CeO} 2$ in anodic environment and also to enhance the density of solid electrolyte.

The main purpose of adding the $\mathrm{Na} 2 \mathrm{CO} 3$ in electrolyte is to create a second phase as a core shell, which also reported previously in our work48-49. This may form a large interface region for ion conduction paths between the SDC and the carbonate at elevated temperatures to greatly enhance the material conductivity48-49. This interface has, in principle, no bulk structural limit for the 
creation of high concentration of mobile ions, and can thus be greatly disordered. This implies that such interfaces have the capacity to contain higher mobile ion concentration than that of the bulk. The electric field distribution in the interfaces between two phases is the key to realizing the interfacial super-ionic conduction, allowing ions to move on particle's surfaces or interfaces by high conductivity pathways.

The higher conductivity of the prepared composite materials at lower temperature is also due to the amorphous nature of $\mathrm{Na} 2 \mathrm{CO} 3$ shell. It can protect the active surface of SDC and interfaces in nanoscale to enhance the nano-material stability as well as further promote the oxygen ion transportation through the interfacial mechanism 47.The use of core-shell co-doped ceria-carbonate nanocomposite electrolytes resulted in a greater conductivity and thermal stability as compared to that of single-phase ceria, and a high ionic conductivity in excess of $0.5 \mathrm{~S} \mathrm{~cm}-1$ at 300-600 oC.

Arrhenius plot was drawn from the total ionic conductivity data by curve fitting to calculate the activation energies (Ea) of the $\mathrm{Sr} 0.1 \mathrm{Sm} 0.1 \mathrm{Ce} 0.8 \mathrm{O} 2-\delta$,-carbonate $\mathrm{Sr} 0.2 \mathrm{Sm} 0.0 \mathrm{Ce} 0.8 \mathrm{O} 2-\delta$-carbonate, $\mathrm{Sr} 0.2 \mathrm{Sm} 0.1 \mathrm{Ce} 0.7 \mathrm{O} 2-\delta$-carbonate, and $\mathrm{Sr} 0.1 \mathrm{Sm} 0.2 \mathrm{Ce} 0.7 \mathrm{O} 2-\delta$-carbonate, nano-composite electrolytes under air atmosphere in the temperature range $300 \mathrm{oC}-650 \mathrm{oC}$ and results is shown in fig. 4(a). It can be seen clearly from the fig $4(\mathrm{a})$ that $\mathrm{S} \mathrm{r} 0.1 \mathrm{Sm} 0.1 \mathrm{Ce} 0.8 \mathrm{O} 2-\delta$-carbonate exhibits high ionic conductivity as compared to the others. Its conductivities increase due to increase of oxygen ions transportation from created large number of oxygen vacancies at high temperature. The doping of strontium in SDC significantly alters its ionic conductivity as reported earlier e.g. T.H.Yeh reported $0.061 \mathrm{~S} / \mathrm{cm}$ at $800 \mathrm{oC}$, N.Jaiswal reported $0.004 \mathrm{~S} / \mathrm{cm}$ at $500 \mathrm{oC}$ and many others reported $30,42,45,52,53$. The change in the ionic conductivity due to the doping of strontium can be related to decrease in lattice binding energy that result into increased numbers of oxygen vacancies. The number of oxygen vacancies is directly related to the conductivity of the material 30,55 . At lower temperature, it has may be less lattice binding energy and defects in the interface phases are not highly mobility for the oxygen ions.

It can also be seen that there is sharply jump around $400 \mathrm{oC}$, where it could be related to glass transition temperature49. The behaviors of conductivities in the air atmosphere was increased with increased the temperature. The enhanced ionic conductivity of co-doped ceria due to strontium doping can be attributed to; (i) maximized non interfering oxygen vacancies, (ii) the average radii of co-doping divalent cations close to that of $\mathrm{Ce} 4+$ and (iii) small average binding energy. The table 2 depicts activation energies due to oxygen ions migration for the prepared samples calculated from the Arrhenius equation.

The ionic transference number ( ion) of ceria co-doped electrolyte was obtained by Hebb-Wagner's DC Polarization method54-55 at $600^{\circ} \mathrm{C}$. The following equation was used for calculation.

Ionic transport number ion $=1$ -

where li and If are the initial current and final current respectively.

The ionic transference numbers ( i) of sample Sr0.1Sm0.1Ce0.8O2- $\delta$-carbonate as calculated using dc polarization technique was found to be 0.90 .

The characteristics curves of I-V/I-R for different temperatures $400{ }^{\circ} \mathrm{C}, 500{ }^{\circ} \mathrm{C}, 580^{\circ} \mathrm{C}$ are represented in fig 4 (b) exhibiting that maximum power density of $900 \mathrm{mWcm}-2$ is achieved at 580 $\mathrm{oC}$. Open circuit voltage (OCV) and current data were recorded for cells (symmetric) at temperature range $400 \circ \mathrm{oC}-580 \mathrm{oC}$, using the Sr0.1Sm0.1Ce0.802- $\delta$-carbonate, as electrolyte and LNCZ-SrSDC as 
electrodes. This sample was used because $\mathrm{Sr} 0.1 \mathrm{Sm} 0.1 \mathrm{Ce} 0.8 \mathrm{O} 2-\delta$-carbonate has the maximum conductivity.

Wenquan et al.,56 achieved a power density of $190 \mathrm{~mW} \mathrm{~cm}-1$ at $800{ }^{\circ} \mathrm{C}$ for the electrolyte La0.9Sr0.1Ga0.8Mg0.2O3 (LSGM) and another research group,56reported an increase in the power density of $170 \mathrm{~mW} \mathrm{cm-1}$ at $1073 \mathrm{~K}$ with SDC electrolyte and Sr-doped samarium cobaltite cathode with the addition of RuO2. However, no report has been seen previously for the calculation of power density of Sr-SDC as an electrolyte. In this present research, a maximum performance has been achieved at low temperature $400-580^{\circ} \mathrm{C}$.

The reduced IR drop from electrolyte ohmic behavior can account for the higher performance at such low temperature. The two phase electrolyte produced by the ceria / carbonate composite, as found, displays a higher ionic conductivity possibly due to enhanced ionic conduction pathways and which makes for the excellent performance demonstrated.

\section{Conclusions}

The results presented in this article show the significant enhancement in the ionic conductivity of the electrolyte which can improve fuel cell performance at lower temperatures. Excellent performance was obtained at $550 \mathrm{oC}$ where a maximum power density of $900 \mathrm{mWcm}-2$ was measured running on excess pure hydrogen at modest pressures and ambient. The ionic conductivity of the best composition of co-doped composite electrolyte was $0.5 \mathrm{~S} / \mathrm{cm}$. The enhanced conductivity is likely to be attributed to the effect of co-doping and of carbonate phases, which leads to a higher ionic conductivity pathways in the electrolyte.

This research provides fundamental studies about co-doped ionic composite conductors which can lead to lower the operating temperature of SOFC. The results using these materials can strongly support the development of the low temperature SOFC for commercialization with an ultra-low cost and reliable performance. At present, the development of composite co-doped electrolyte materials and its application in LT-SOFCs are still at an initial stage. Development of SOFC technology operating at 300-600 oC also opens up new market opportunities.

\section{Acknowledgements}

Authors acknowledge Indigenous scholarship, Higher Education Commission (HEC), the start-up research grant from Higher Education Commission (HEC), Pakistan and COMSATS Research Grant Program (CRGP) to support this work.

\section{References}

N. Q. Minh, T. Takahashi, Science and Technology of Ceramic Fuel Cells, Elsevier, Amsterdam, (1995).

O. Parkash, N. Singh, N. K. Singh, D. Kumar, Solid State Ionics,2012, 212, 100-105.

D. J. L. Brett, A. Atkinson, N. P. Brandon and S. J. Skinner, Chem. Soc. Rev., 2008, 37, 15681578.

D.S. Lee, W.S. Kim, S.H. Choi, J. Kim, H.W. Lee and J.H. Lee, Solid State lonics,2005,176, $33-$ 39.

M. Burbano, S. Nadin, D. Marrocchelli, M. Salanne and G. W. Watson, Phys. Chem. Chem.,2014,16, 8320. 
V.V. Kharton, E. N. Naumovich and A. A. Vecher, J. Solid State Electrochem.,1999,3, 61-81.

S. Omar, E. D. Wachsman and J. C. Nino, Solid State lonics,2006,177, 3199.

R. M. Ormerod, Chem. Soc. Rev., 2003,32,17-28.

V.V. Kharton, F.M.B.Marques and A. Atkinson, Solid State Ionics,2004, 174, 135-149.

P. Lacorre, F. Goutenoire, O. Bohnke, R. Retoux and Y. Laligant, Nature, 2000,404, 856-858.

E. Kendrick, M. S. Islam, P. R. Slater and J. Mater,Chem., 2007,17, 3104-3111.

J. C. Boivin and G. Mairesse, Chem. Mater.,1998,10, 2870-2888.

X. Kuang, M. A. Green, H. Niu, P. Zajdel, C. Dickinson, J. B. Claridge, L. Jantsky and M. J. Rosseinsky, Nat. Mate.,2008,7, 498-504.

H. A. Harwig and A. G. Gerards, J. Solid State Chem.,1978,26, 265-274.

H. A. Harwig and A. G. Gerards, Thermochim. Acta.,1979, 28, 121-131.

R. Punn, A. M. Feteira, D. C. Sinclair and C. Greaves, J. Am. Chem.Soc.,2006,128, 1538615387.

M. Benkaddour, S. Obbade, P. Conflant and M. Drache, J. Solid State Chem.,2002,163, 300307.

H. Inaba and H. Tagawa, Solid State Ionics, 1996, 83, 1-16.

B. C. H. Steele, Solid State Ionics,2000, 129, 95-110.

R. Raza, G. Abbas, Y. Ma, X. Wang and B. Zhu, Solid State lonics, 2011,188, 58-63.

P. P. Dhlabhai, J. B. Adams, P. Crozier and R. Sharma, J. Chem. Phys., 2010,132, 094104.

C. Peng, Y. N. Liu and Y. X. Zheng, Mater. Chem. Phys., 2003, 82, 509.

P. P. Sahoo, J. L. Payne, M. Li, J. B. Claridge and M. J. Rosseinsky, Journal of Physics and Chemistry of Solids,2015,76, 82-87.

M. Mogensen, N. M. Sammers and G. A. Tompsett, Solid State lonics,2000, 129, 63.

A. Ismail, J. Hooper, J.B. Giorgi and T.K. Woo, Phys. Chem. Chem. Phys., 2011, 13, 6116.

D.J. Kim, J. Am. Ceram. Soc., 1989, 72, 1415.

J. Kilner, Solid State Ionics, 1983, 8, 201.

Y.Y. Liu, B. Li, X. Wei and W. Pan, J. Am. Ceram. Soc., 2008, 91, 3926.

S. Omar, E.D. Wachsman and J.C. Nino, Solid State lonics, 2008,178, 1890.

T.H. Yeh and C.C. Chou, Phys. Scr.T129, 2007, 303-307.

H. Yahiro, K. Eguchi and H. Arai, Solid State Ion, 1989, 36,71-75.

C.T. Chen, S. Sen and S. Kim, Chem. Mater., 2012, 24, 3604-3609.

K. Eguchi, T. Setoguchi, T. Inoue and H. Arai, Solid State Ionics, 1992, 52, 165. 
J. A. Kilner and R. J. Brook, Solid State lonics, 1982, 6, 237.

C. R. A. Catlow, Solid State lonics, 1984, 12, 67.

R.D. Shannon, ActaCrystallogr. Sect., A 32, 1976, 751.

T.I. Politova and J.T.S. Irvine,Solid State Ionics, 2004, 168, 153-165.

N. Kim , B. H. Kim and D. Lee, Electrochemical Society Proceedings 99-19 (1999) 201-08.

H.Yamamura, E. Katoh, M. Ichikawa, K. Kakinuma, T. Mori and H. Haneda, Electrochemistry,2000,68,455-59.

H. Yoshida, H. Deguchi, K. Miura, M. Horiuchi and T. Inagaki, Solid State lonics,2001, 140,191-199.

D.A. Andersson, S. I. Simak, N. V. Skorodumova, I. A. Abrikosov and B. Johansson, Proc. Natl. Acad. Sci. USA.,2006,103, 3518-3521.

S. Omar, E. D. Wachsman and J. C. Nino, Solid State Ionics, 2008,178, 1890-1897.

S. Ramesh and K. C. J. Raju, Int. J. Hydrog. Energy, 2012, 37, 10311-10317.

X. Sha, Z. Lü, X. Huang, J. Miao, Z. Ding, X. Xin and W. Su. Journal of Alloys and Compounds, $2007,428,59-64$.

Z. Gao, X. Liu, B. Bergman and Z. Zhao, Journal of Power Sources,2012,208, 225-231.

X.Sha, Z. Lü, X. Huang, J. Miao, Z. Ding, X. Xin and W. Su, J. Alloys Compd.,2007,428, 59.

R. Raza, X. Wang, Y. Ma and B. Zhu, J. Power Sources,2010,195, 6491.

X. Wang, Y. Ma, R. Raza, M. Muhammed and B. Zhu, Electrochemistry Communications,2008,10, 1617-1620.

Y. Ma, X. Wang, R. Raza, M. Muhammed and B. Zhu, International Journal of Hydrogen Energy, 2010,35, 2580-2585.

H. M. Li, Q. C. Zhu, Y. L. Li, M. C. Gong, Y. D. Chen, J. L. Wang and Y. Q. Chen, J. Rare Earths,2010,28, 79.

B.D. Cullity, Elements of X-Ray Diffraction, Addison-Wesley, Reading, MA. 1956.

B. Zhu and M. D. Mat, Int. J. Electrochem. Sci.,2006,1, 383-402.

N. Jaiswal , S. Upadhyay, D. Kumar, O.Parkash, Journal of Power Sources,2013, 222 , 230-236

C. Wagner, Z. Phys. Chem, 1933, B21, 25-47.

M. H.Hebb, J. Chem. Phys., 1952,20, 185-190.

G. Wenquan,G. Srikanth and B. P. Uday, Journal of Power Sources, 160 2006,160, 305-315. 


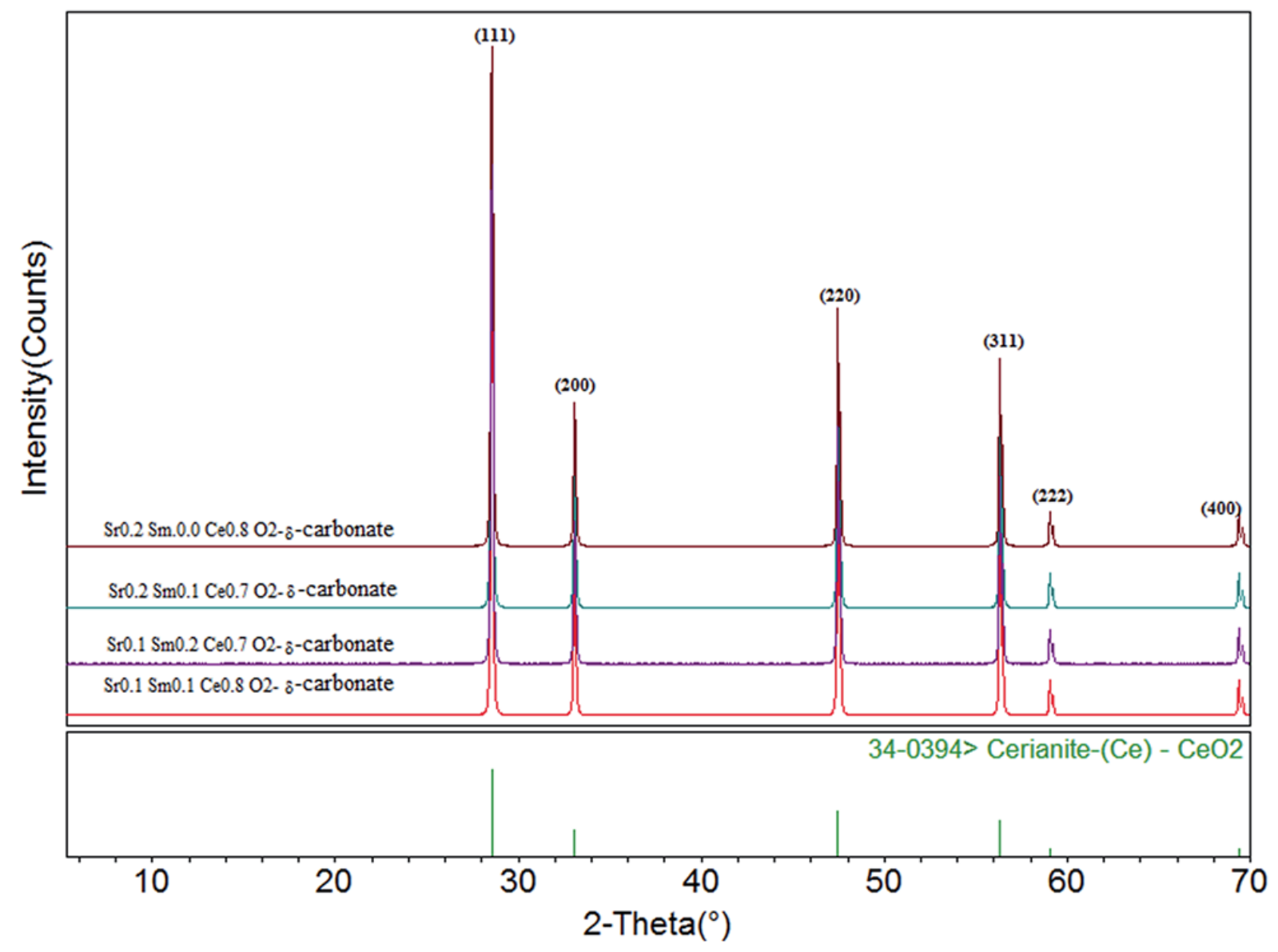

Fig. 1 X-ray diffraction pattern for different compositions of Sr/Sm ceria-carbonate electrolytes.

\begin{tabular}{|c|c|c|c|}
\hline Sr. No. & Composition & $\begin{array}{l}\text { Crystallite size of } \\
\text { Sintered Powder } \\
(\mathrm{nm})\end{array}$ & $\begin{array}{l}\text { Lattice Parameter } \\
(\AA)\end{array}$ \\
\hline 1 & $\mathrm{Sr}_{0.2} \mathrm{Sm}_{0.0} \mathrm{Ce}_{0.8} \mathrm{O}_{2-\delta}$ & 47.898 & 5.4037 \\
\hline 2 & $\mathrm{Sr}_{0.2} \mathrm{Sm}_{0.1} \mathrm{Ce}_{0.7} \mathrm{O}_{2-\delta}$ & 43.239 & 5.4186 \\
\hline 3 & $\mathrm{Sr}_{0.1} \mathrm{Sm}_{0.2} \mathrm{Ce}_{0.7} \mathrm{O}_{2-\delta}$ & 31.276 & 5.4227 \\
\hline 4 & $\mathrm{Sr}_{0.1} \mathrm{Sm}_{0.1} \mathrm{Ce}_{0.8} \mathrm{O}_{2-\delta}$ & 56.637 & 5.4258 \\
\hline
\end{tabular}

Table 1 Lattice parameters of $\mathrm{Sr} / \mathrm{Sm}$ ceria-carbonate electrolytes with different composition 
(a)
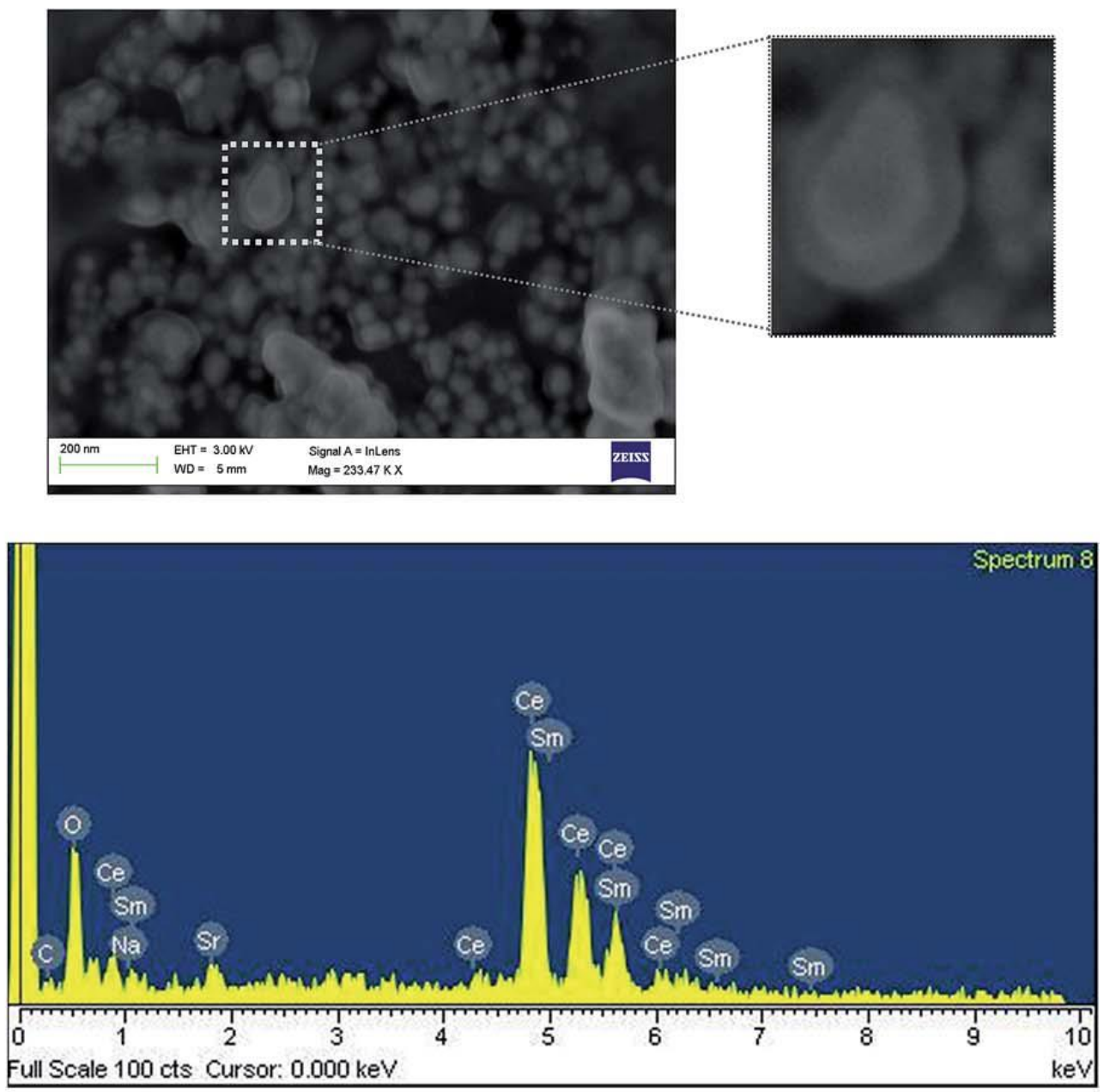

(b)

Full Scale $100 \mathrm{cts}$ Cursor: $0.000 \mathrm{keV}$ $\mathrm{keV}$

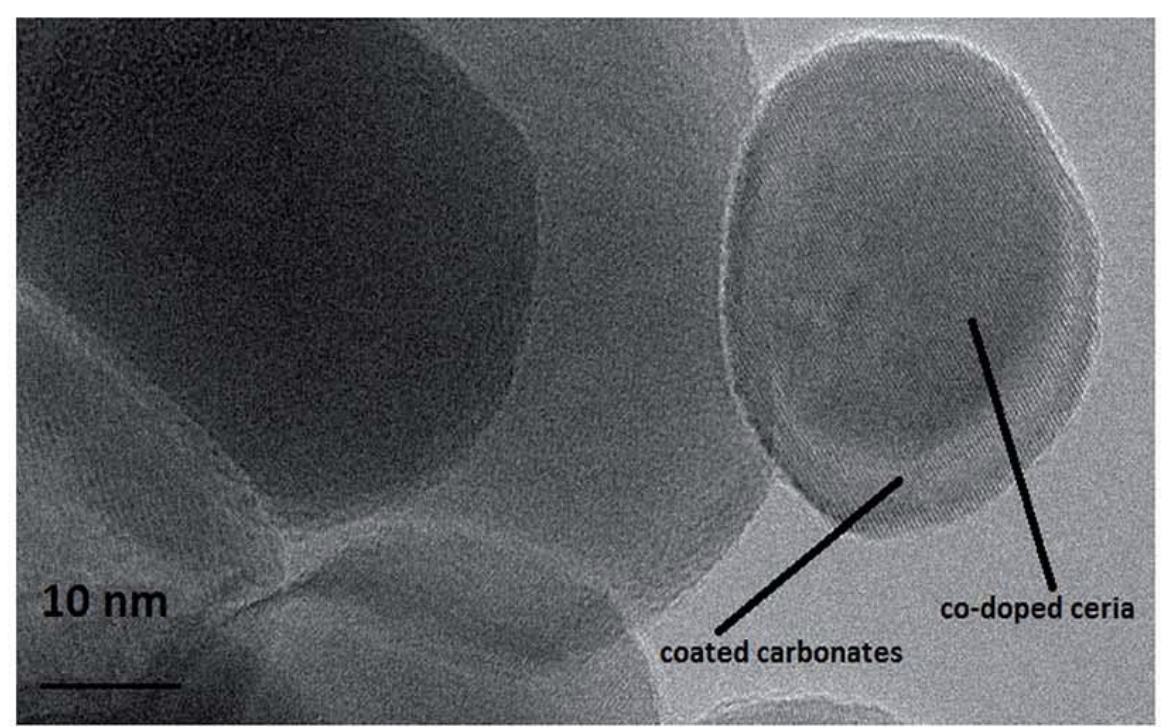

Fig. 2 (a) SEM micrograph for Sr0.1Sm0.1Ce0.8O2 d-carbonate with closed view of core shell particles (b) EDX spectrum of co-doped ceria with $\mathrm{Sr} / \mathrm{Sm}$-carbonate (c) TEM micrograph for Sr0.1Sm0.1Ce0.8O2 d- carbonate core shell. 

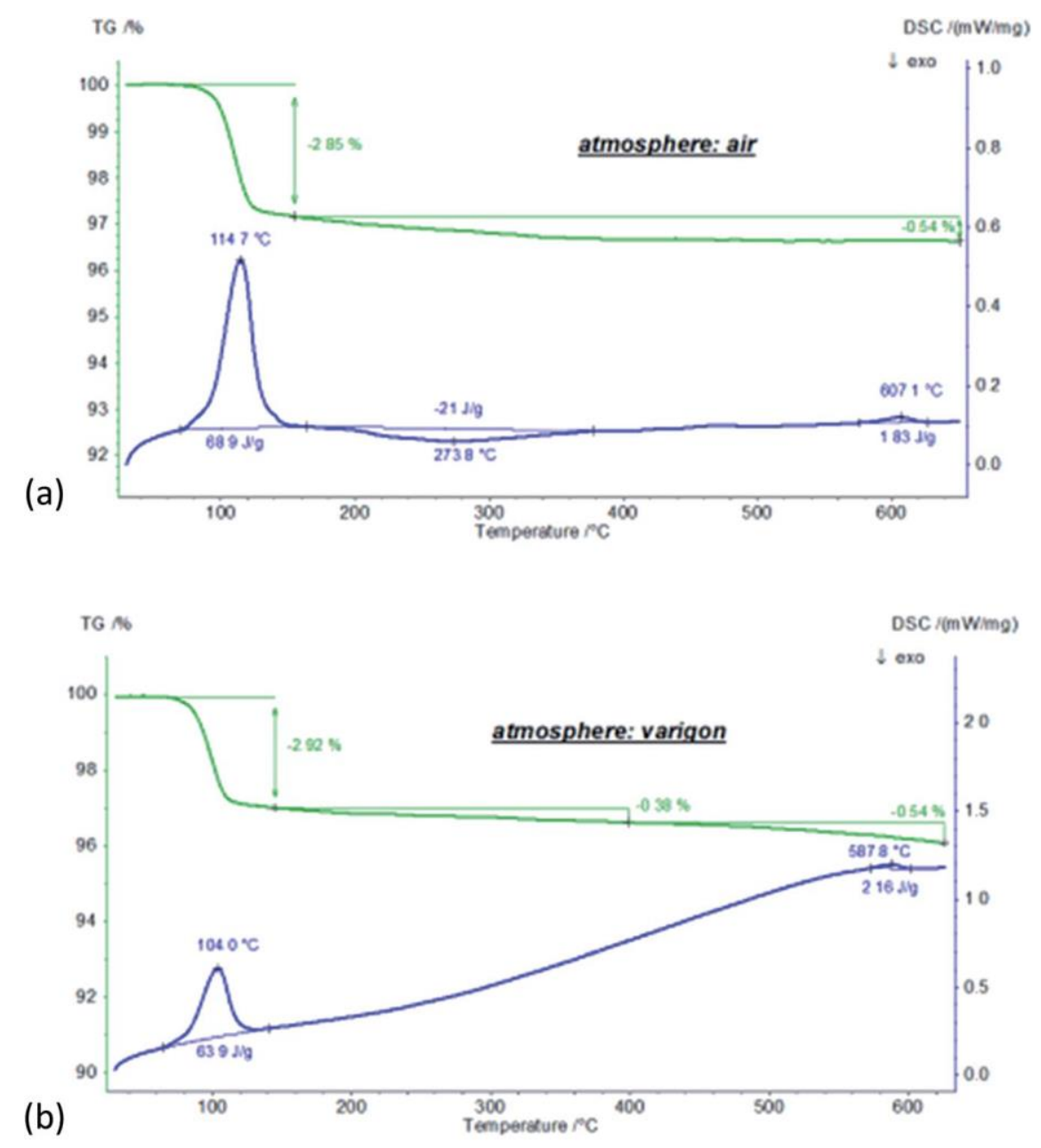

(c)

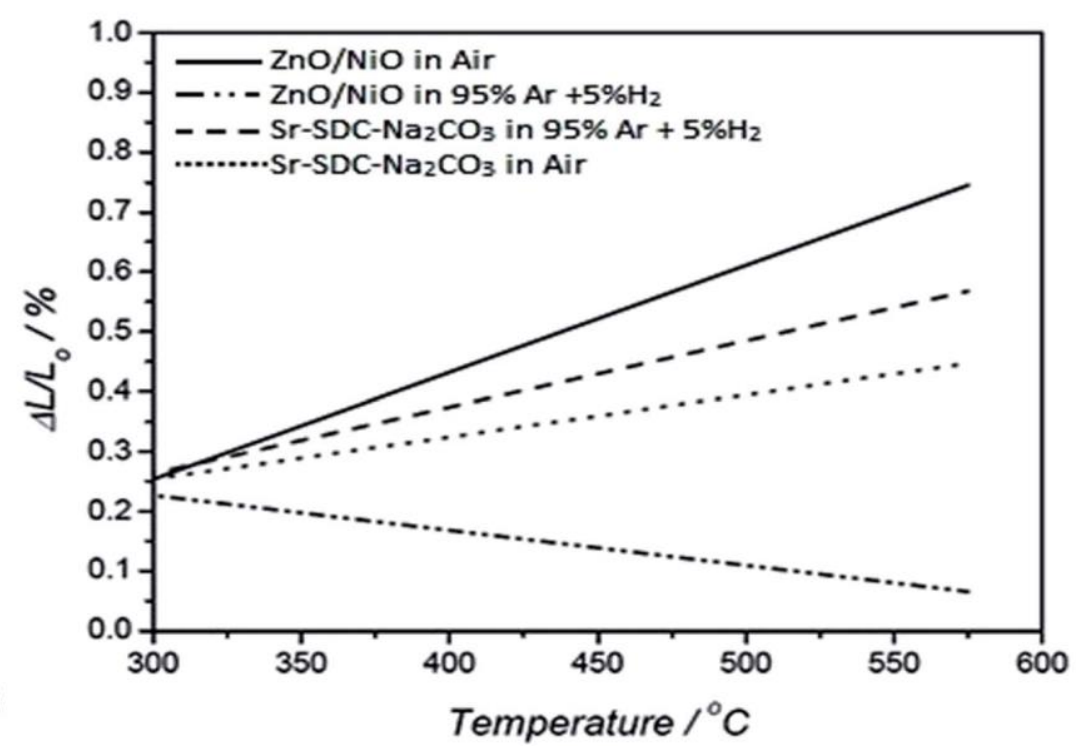

Fig. 3 (a) TGA/DSC of Sr/Sm ceria-carbonate electrolytes with a ramp rate of $10 \mathrm{C}$ $\min$ 1 in $\mathrm{H} 2$ atmosphere, (b) TGA/DSC of Sr/Sm ceria- carbonate electrolytes with a ramp rate of $10 \mathrm{C} \mathrm{min}$ 1 in argon atmosphere, (c) thermal expansion of $\mathrm{ZnO} / \mathrm{NiO}$ and $\mathrm{Sr} / \mathrm{SDC}$-carbonate both in air and $\mathrm{H} 2$ (diluted with argon), in which $D L / L$ is the relative variation of the length of the samples. 


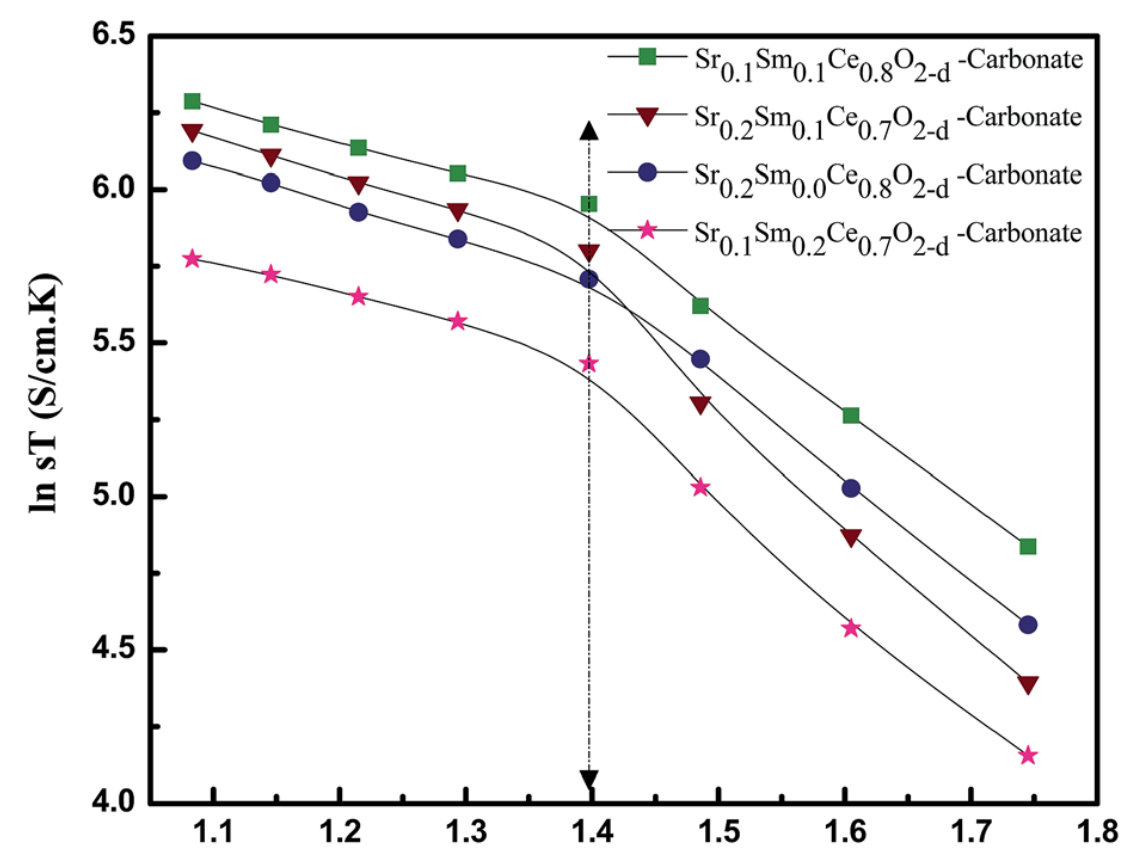

(a)
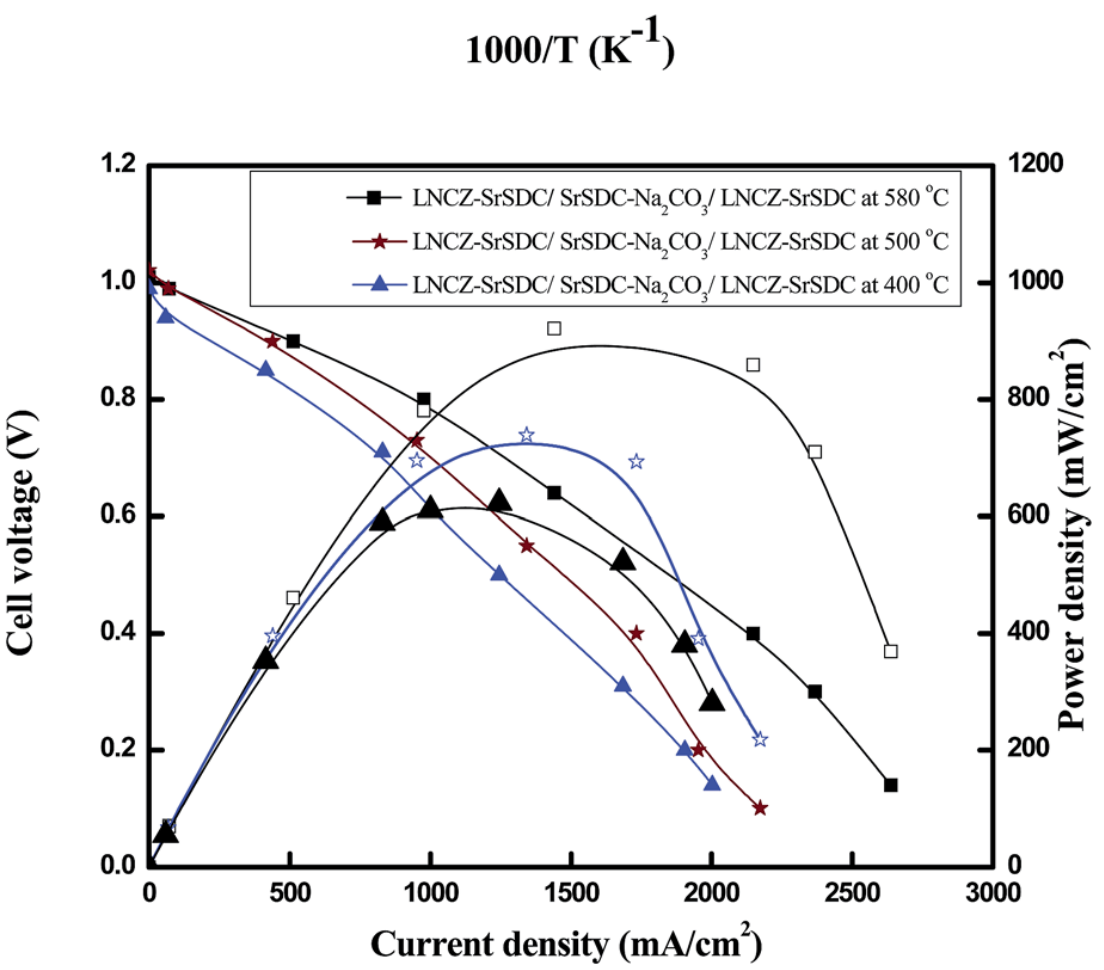

Fig. 4 (a) Arrhenius plot for different Sr/Sm ceria-carbonate electrolytes in air (b) I-V/I-P characteristics of a fuel cell at different temperatures 400 C, 500 C, 580 C.

\begin{tabular}{ll}
\hline Composition & $\begin{array}{l}\text { Activation Energy } \\
(\mathrm{eV})\end{array}$ \\
& $300-650{ }^{\circ} \mathrm{C}$ \\
\hline $\mathrm{Sr}_{0.2} \mathrm{Sm}_{0.0} \mathrm{Ce}_{0.8} \mathrm{O}_{2-\delta}$ & 0.23 \\
$\mathrm{Sr}_{0.2} \mathrm{Sm}_{0.1} \mathrm{Ce}_{0.7} \mathrm{O}_{2-\delta}$ & 0.24 \\
\hline
\end{tabular}




\begin{tabular}{ll}
\hline $\mathrm{Sr}_{0.1} \mathrm{Sm}_{0.2} \mathrm{Ce}_{0.7} \mathrm{O}_{2-\delta}$ & 0.21 \\
$\mathrm{Sr}_{0.1} \mathrm{Sm}_{0.1} \mathrm{Ce}_{0.8} \mathrm{O}_{2-\delta}$ & 0.20
\end{tabular}

Table 2: Activation energy (eV) for different compositions at $300-650{ }^{\circ} \mathrm{C}$ 